\title{
POR QUE MARCAS CORPORATIVAS? A PERCEPÇÃO DE EXECUTIVOS BRASILEIROS SOBRE OS MOTIVOS PARA ADOTAR CORPORATE BRANDING
}

\author{
Juliana Rodrigues ${ }^{2}$ \\ Ney Nakazato Miyahira ${ }^{3}$ \\ Fernando Nascimento ${ }^{4}$ \\ Bernadete de Lourdes Marinho ${ }^{5}$
}

http://dx.doi.org/10.1590/1413-2311.154.57163

\begin{abstract}
RESUMO
O conceito de Marca Corporativa apresenta ampla aplicação e escopo da gestão, gerando diversos motivos que levam a opção por esta estratégia. O objetivo do estudo é entender quais são os motivos percebidos como relevantes para adotar a marca corporativa, bem como quais as abordagens mais proeminentes entre executivos brasileiros. Este estudo, de natureza descritiva e quantitativa, envolveu o mapeamento dos principais motivos abordados na literatura e uma survey com 275 gestores de empresas de diferentes segmentos, todas atuantes no Brasil. Neste estudo, a definição de "principais motivos" adotada refere-se às razões percebidas como relevantes para a opção por uma estratégia de marca corporativa, incluindo referenciais de resultados esperados, benefícios percebidos e premissas de atuação de mercado. Os resultados indicam a predominância da visão da marca corporativa como meio de comunicar os valores, seguida da escola voltada para a construção da imagem positiva. Entre os motivos mais relevantes, o fortalecimento das marcas dos produtos e o foco nos consumidores chama mais atenção, seguido de fortalecimento de identidade em multinacionais. $\mathrm{O}$ estudo contribui com o mapeamento abrangente dos motivos para esta estratégia e a visão sobre quais as perspectivas predominantes no mercado brasileiro.
\end{abstract}

Palavras-Chave: Marca Corporativa. Corporate Branding. Ativos Intangíveis. Reputação. Marketing Corporativo.

\section{WHY CORPORATE BRANDS? THE BRAZILIAN EXECUTIVES PERCEPTION ON THE REASONS FOR ADOPTING CORPORATE BRANDING}

\footnotetext{
ABSTRACT

${ }^{1}$ Recebido em 18/07/2015; aprovado em 16/03/2017.

${ }^{2}$ Faculdade de Economia, Administração e Contabilidade da Universidade de São Paulo - jurodrigues@usp.br.

${ }^{3}$ Faculdade de Economia, Administração e Contabilidade da Universidade de São Paulo - neymiyahira@usp.br.

${ }^{4}$ Faculdade de Economia, Administração e Contabilidade da Universidade de São Paulo fernandonascimento.usp@gmai.com.

${ }^{5}$ Faculdade de Economia, Administração e Contabilidade da Universidade de São Paulo - marinhoy@ usp.br. REAd | Porto Alegre - Vol. 23 - No Especial - Dezembro 2017 - p. 232-261
} 
The concept of Corporate Brand presents wide application and management scope, generating several reasons that lead to this strategic option. The purpose of the study is to understand the reasons perceived as being relevant for adopting the corporate brand, as well as the most prominent approaches among Brazilian executives. This descriptive and quantitative study included the mapping of the main reasons discussed in the literature and a survey with 275 company managers from different segments, all operating in Brazil. In this study the definition of "main reasons" is related to the motives perceived as relevant to adopt the corporate branding strategy, including references to expected results, perceived benefits and perspectives of market practice. The findings indicate the predominance of the corporate brand view as a means for communicating the values, followed by the choice related to the positive image building. Among the most relevant reasons, the strengthening of products trademarks and the focus on consumers draw more attention, followed by the identity strengthening in multinational companies. The study contributes to the comprehensive mapping of the reasons for this strategy and to the vision about what are the prevalent perspectives in the Brazilian market.

Keywords: Corporate Brand. Corporate Branding. Intangible Assets. Reputation. Corporate Marketing.

\section{¿POR QUÉ MARCAS CORPORATIVAS? LA PERCEPCIÓN DE DIRECTIVOS BRASILEÑOS SOBRE LOS MOTIVOS PARA ADOPTAR CORPORATE BRANDING.}

\section{RESUMEN}

El concepto de Marca Corporativa tiene amplia aplicación y alcance en la gestión, generando diversos motivos que llevan a optar por esta estrategia. El objetivo en este estudio es entender cuáles son los motivos considerados relevantes para adoptar la marca corporativa, así como qué enfoques son preponderantes entre directivos brasileños. Se lleva a cabo un estudio, descriptivo y cuantitativo, en que se determinan y analizan los principales motivos que figuran en la literatura, y se aplica una encuesta a 275 gerentes de empresas de segmentos variados, resaltando que todas estas empresas actúan en Brasil. En este estudio la definición de "principales motivos" hace referencia a las razones percibidas como relevantes para la elección de una marca corporativa, incluyendo los resultados estimados esperados, los beneficios percibidos y las premisas de actuación en el mercado. Los resultados indican el predominio de la visión de la marca corporativa como medio para comunicar los valores, seguida de la escuela dirigida a la construcción de la imagen positiva. Entre los motivos más relevantes, resaltan el fortalecimiento de las marcas de los productos y el foco en los consumidores, seguidos del fortalecimiento de identidad en multinacionales. El estudio contribuye con un amplio análisis de los motivos que llevan a la adopción de esta estrategia y la visión sobre las perspectivas predominantes en el mercado brasileño.

Palabras Clave: Marca Corporativa. Corporate Branding. Activos Intangibles. Reputación. Marketing Corporativo.

\section{INTRODUÇÃO}

REAd | Porto Alegre - Vol. 23 - No Especial - Dezembro 2017 - p. 232-261 
Em um mundo cada vez mais conectado, no qual a informação circula de maneira rápida e integrada, as regras do jogo mudaram, tornando-se complexas e sistêmicas. Da globalização dos mercados ao crescente poder das tecnologias de informação, a natureza da corporação moderna mudou radicalmente (FREEMAN; HARRISON; WICKS, 2007). Já não é apenas na lógica de produto que a empresa precisa interagir com seus públicos (AAKER, 2004).

As pessoas e a sociedade estão diferentes e cobram das organizações, de forma constante e intensa, uma postura mais participativa e sustentável, além de simplesmente vender produtos e serviços (BALMER; GRAY, 2003; HATCH; SCHULTZ, 2003, 2008; KNOX; BICKERTON, 2003; ARGENTI, 2005; BALMER, 2010, 2012). Ao entender negócios como um conjunto estratégico de relacionamento com stakeholders para criar valor (FREEMAN; HARRISON; WICKS, 2007), a marca corporativa se torna a principal expressão da empresa, a identidade comunicada e projetada (KING, 1991; BALMER, 2001, 2012; BALMER; GRAY, 2003; HATCH; SCHULTZ, 2003; VAN RIEL; FOMBRUN, 2007; URDE, 2009; ABRATT; KLEYN, 2012; FETSCHERIN; USUNIER, 2012; PÉREZ; DEL BOSQUE, 2014).

Na visão macro, a marca corporativa faz parte da estratégia corporativa na gestão dos ativos intangíveis e mecanismo de diferenciação entre seus concorrentes (HATCH; SCHULTZ, 2003; URDE; GREYSER, 2016). A função da marca corporativa torna-se a representação e a personalidade da organização no relacionamento com os stakeholders (ABRATT; KLEYN, 2012), reforçando e ampliando o papel tradicional do marketing e a comunicação do foco principal voltado somente ao produto para abranger a organização como um todo (BALMER, 2001). Os processos de corporate branding consistem numa série de atividades planejadas e executadas por uma organização para construir associações favoráveis e reputação positiva tanto com stakeholders internos quanto externos (VAN RIEL; FOMBRUN, 2007).

A abordagem de marca corporativa vem evoluindo, sendo adotada por autores de diferentes áreas, sob perspectivas e enfoques variados, com predominância nas áreas de negócios, gestão, arquitetura, artes e comunicação (FETSCHERIN; USUNIER, 2012). O aumento de interesse em marca corporativa nas últimas décadas levou a uma série de refinamentos e vertentes em sua definição, resultando numa ampla extensão de aplicação e escopo da gestão de marca corporativa (KNOX; BICKERTON, 2003; ABRATT; KLEYN, 2012; FETSCHERIN; USUNIER, 2012; PÉREZ; DEL BOSQUE, 2014).

REAd | Porto Alegre - Vol. 23 - No Especial - Dezembro 2017 - p. 232-261 
Ainda que, de maneira geral, trate-se do alinhamento interno e externo da proposta de valor da empresa (BALMER, 2001; HATCH; SCHULTZ, 2003; URDE, 2003; SHEIKH; LIM, 2011; ABRATT; KLEYN, 2012), diferentes tons são aplicados para definição de marca corporativa e principais motivos que levam à opção por esta estratégia. Por exemplo, sob o ponto de vista de marketing e do relacionamento com o cliente e consumidor, a definição representa a empresa que está por trás de determinados produtos e serviços (AAKER, 2004). Para estudiosos voltados para a comunicação corporativa, é relacionada à narrativa e engajamento de stakeholders na construção de uma reputação positiva e favorável (VAN RIEL; FOMBRUN, 2007). Há, ainda, os benefícios financeiros de uma marca corporativa forte e de seu ativo intangível (GLYNN; MOTION; BRODIE, 2007; KOTLER; PFOERTSCH, 2007). Na área de gestão de pessoas, o enfoque é dado tanto internamente, no sentimento de pertencer e importância emocional para o público interno (BAUMGARTH; SCHMIDT, 2010), quanto na atração e reforço da empregabilidade na abordagem da marca como empregadora, o employer brand (BACKHAUS; TIKOO, 2004; EDWARDS, 2010; SINGH; JAIN, 2013).

Apesar da ampla evolução sobre o tema, a proliferação de abordagens, conceitos e motivos defendidos para a importância e os benefícios da marca corporativa, ainda não há clareza sobre quais os fatores são mais relevantes e como os gestores, em geral, percebem esta estratégia. Ao mesmo tempo em que altos executivos e suas equipes de gestão reconhecem a importância da criação e manutenção de excelentes reputações e marcas fortes, não há clareza sobre o que este processo implica em sua totalidade (ABRATT; KLEYN, 2012). Essa pesquisa visa contribuir para o preenchimento de algumas lacunas apontadas por Fetscherin e Usunier (2012) no que tange as escolas de marca corporativa, inspiradas pela classificação proposta por Balmer e Gray (2003), bem como a contribuição de um estudo empírico aplicado ao contexto gerencial no Brasil.

Neste cenário, o presente estudo busca responder ao problema de pesquisa sobre quais são os principais motivos para adotar corporate branding. Para isso, foi realizada uma revisão da literatura sobre diferentes razões defendidas como importantes para optar por esta estratégia, bem como traçado um retrato preliminar sobre a percepção dos executivos brasileiros investigados por meio de uma pesquisa survey. Os objetivos específicos são: (1) detectar a hierarquia de motivos percebidos como relevantes para adoção da marca corporativa; e (2) identificar as abordagens predominantes de marca corporativa entre os executivos que atuam no país, a fim de compreender como tais conceitos e abordagens são 
percebidos na prática corporativa no país.

Os principais motivos estão relacionados ao processo de tomada de decisão, isto é, uma escolha entre alternativas ou possibilidades, que considera a razão, motivo e racionalidade que impulsiona a determinada ação (BAZERMAN; MOORE, 2010). Neste estudo, a definição de "principais motivos" adotada refere-se às razões percebidas como relevantes para a opção por uma estratégia de marca corporativa, incluindo referenciais de resultados esperados, benefícios percebidos e premissas de atuação de mercado, envolvendo: guerra por Talentos (Employer Branding); sinergia entre as marcas de produto e da empresa; Atração de clientes e consumidores; relações comerciais, em especial em segmentos businessto-business; multinacionais e holdings; reposicionamento estratégico; demanda por transparência; Face única com stakeholders, responsabilidade social e sustentabilidade; mercado de capitais; identidade organizacional; imagem, reputação e ativo intangível.

Neste contexto, o termo "adotar Corporate Branding" - Estratégia de Marca Corporativa - é entendido como a escolha intencional por investir de maneira constante no processo de reconhecimento e construção de associações positivas sobre a organização no relacionamento com um ou mais stakeholders a partir do trabalho voltado à marca corporativa (VAN RIEL; FOMBRUN, 2007). O termo marca corporativa inclui a ideia de marca da empresa, porém amplia sua abrangência com foco tanto interno, quanto externo (BLOMBÄCK; RAMÍREZ-PASILLAS, 2012), e considera uma grande variedade de entidades corporativas, incluindo empresas, corporações, subsidiárias, grupos de empresas e associações de marcas (BALMER; GRAY, 2003; VAN RIEL; FOMBRUN, 2007; FETSCHERIN; USUNIER, 2012).

O artigo está estruturado em quatro partes, além dessa introdução. A primeira apresenta a revisão da literatura realizada, com foco no mapeamento dos motivos relatados em diferentes áreas para adoção de corporate branding, bem como as nuances que diferenciam as "escolas" conceituais que utilizam o conceito de marca corporativa. Na sequência, é abordado o método aplicado na realização de uma pesquisa quantitativa, por survey, com 275 executivos brasileiros de empresas e portes variados. A terceira parte traz os principais resultados consolidados da pesquisa. A ordenação das motivações foi realizada pela análise hierárquica de processos (AHP) e a mais relevante foi que "a marca corporativa pode fortalecer as marcas de produtos". Também foi aplicada a análise fatorial exploratória, técnica multivariada de interdependência, a fim de verificar o possível agrupamento e redução dos motivos a partir das respostas dos entrevistados. Para investigar a associação das motivações 
com os perfis dos executivos foram realizadas análises discriminantes pelo método de Fisher, entretanto a amostra não apresentou evidência de associação. A última parte apresenta as conclusões principais do estudo realizado até o momento, bem como as limitações e implicações acadêmicas e gerenciais dos resultados.

\section{REFERENCIAL TEÓRICO}

O processo de construção de marcas começou mais fortemente atrelado a produtos e serviços, porém, gradativamente as empresas foram percebendo valor em também criar marcas corporativas, pela influência da organização atrás dos produtos e serviços (AAKER, 2004; KNOX; BICKERTON, 2003). O termo marca corporativa surge ainda na década de 1970, porém com foco mais na abordagem gerencial do que acadêmica (FETSCHERIN; USUNIER, 2012).

No início de 1990, o conceito de marca corporativa começou a ganhar força como a atuação da "marca da empresa" e a apresentação da organização responsável pela fabricação daquele produto, ou prestação do serviço, seus valores e a atração de pessoas que se identificam com a proposta da empresa (AAKER, 2004; FETSCHERIN; USUNIER, 2012; KING, 1991; KNOX; BICKERTON, 2003). Está relacionada com a estratégia empresarial (BALMER; GRAY, 2003), representando uma ferramenta importante de gestão (HATCH; SCHULTZ, 2003; GOTSI; ANDRIOPOULOS; WILSON, 2008), embora, muitas vezes, o processo de construção da marca corporativa seja mais informal e pouco planejado (BLOMBÄCK; RAMÍREZ-PASILLAS, 2012). A marca corporativa pode ser considerada uma das capacidades intangíveis com potencial de estabelecer uma vantagem competitiva (GHAURI et al., 2011; ABRATT; KLEYN, 2012; URDE; GREYSER, 2016).

Um importante movimento que também fortaleceu a criação de marcas corporativas esteve atrelado a empresas business-to-business (B2B), ao reconhecer o valor e a vantagem competitiva de ter uma marca corporativa forte em suas negociações com outras empresas, envolvendo a criação de significado, imagem e reputação para a empresa como um todo (GLYNN; MOTION; BRODIE, 2007; KELLER; MACHADO, 2006; KOTLER; PFOERTSCH, 2007; LEEK; CHRISTODOULIDES, 2011; SHEIKH; LIM, 2011). Outra vertente importante são os negócios sem fins lucrativos e ONGs (KELLER; MACHADO, 2006). Como construção de posicionamento e significado, as marcas em geral, de produtos e de empresas, guardam princípios semelhantes, porém com especificidades significativas 
(BALMER, 2001; KING, 1991), como mostra o Quadro 1.

Quadro 1 - Marcas de produto versus Marcas Corporativas

\begin{tabular}{|lcc|}
\hline & Marcas de Produtos & Marcas Corporativas \\
\hline Gestão & Gerente / Diretor & CEO \\
\hline Responsabilidade & Gerente / Diretor & Todas as pessoas \\
\hline Disciplina cognata & Marketing & Estratégia multidisciplinar \\
\hline Mix de Comunicação & Comunicação de Marketing & Comunicação Corporativa Total \\
\hline Foco & Predominantemente consumidor & $\begin{array}{l}\text { Múltiplos, stakeholders internos e } \\
\text { externos, redes de relacionamento }\end{array}$ \\
\hline Valores & Elaborados / propostos & Elementos da cultura \\
\hline
\end{tabular}
Fonte: adaptado de BALMER (2001, tradução nossa).

O posicionamento da marca corporativa envolve a história, pessoas, ativos, capacidades, valores e a noção de um papel positivo de cidadania da empresa (AAKER, 2004), conferindo sua personalidade (DAVIES; CHUN, 2002). Os pontos de contato aumentam em quantidade e diversidade, incluindo diferentes stakeholders, como empregados, e os mais distantes, como comunidade, imprensa e governos, exigindo novas formas de comunicação e relacionamentos (KING, 1991; BALMER, 2001; DAVIES; CHUN, 2002; BALMER; GRAY, 2003; HATCH; SCHULTZ, 2003; KNOX; BICKERTON, 2003; KAY, 2006; ABRATT; KLEYN, 2012).

A marca corporativa é, então, diferente da marca do produto no seu escopo e gestão. Portanto, requer uma revisão conceitual, pois a tradicional visão de marketing não é totalmente aplicável (BALMER; GRAY, 2003; BALMER, 2001). Tudo o que a empresa faz comunica e deve ser articulada em toda a organização, especialmente no comportamento dos empregados em todas as interfaces (DAVIES; CHUN, 2002; HARRIS; CHERNATONY, 2001; HATCH; SCHULTZ, 2003; KNOX; BICKERTON, 2003; SCHULTZ; CHERNATONY, 2002).

O comportamento da organização como um todo deve ser consistente com a proposta de valor que a marca corporativa pretende passar, pois essa ampla gama de públicos exercita uma maior variedade de distinções de outros elementos intangíveis, além dos já convencionados elementos tangíveis de produto/serviço (KING, 1991; KNOX; BICKERTON, 2003; AAKER, 2004; ARGENTI; DRUCKENMILLER, 2004; ABRATT; KLEYN, 2012; URDE; GREYSER, 2016). Por isso, deixa de ser o papel de um departamento, para ser o papel da empresa de forma integrada (BALMER; GRAY, 2003; HATCH; SCHULTZ, 2003; KING, 1991). 
Torna-se importante estrategicamente não apenas pelo posicionamento no mercado, mas também por favorecer a criação de mecanismos internos, como estrutura, infraestrutura e cultura que suportem a promessa de valor daquela organização (HATCH; SCHULTZ, 2003). A marca corporativa endereça a diferenciação e o pertencimento, externo e interno (AAKER, 2004; DAVIES; CHUN, 2002; HATCH; SCHULTZ, 2003). Deve representar os valores essenciais, dando forma e direcionamento para as crenças mais valiosas da organização (URDE, 2003), sendo inclusive uma vantagem competitiva na realidade atual de mercado, com pouca diferenciação entre produtos, mercados fragmentados e globalizados (AAKER, 2004; HATCH; SCHULTZ, 2003).

Em suma, a gestão de marca corporativa (corporate branding) compreende a construção focada e intencional de associações positivas com os stakeholders, ou seja, um processo planejado e implementado de criar e manter imagens favoráveis e, consequentemente, reputação favorável da organização como um todo, por meio da transmissão de sinais e indícios a todos stakeholders a partir da gestão de comportamento, comunicação e simbolismo (EINWILLER; WILL, 2002).

Embora se utilize de princípios similares ao branding em geral, a marca corporativa representa um escopo mais amplo de marketing corporativo (BALMER, 2001; PÉREZ; DEL BOSQUE, 2014). O enfoque na marca corporativa confere maior ênfase ao nível institucional da organização ao reforçar esses elementos tangíveis e intangíveis mais duráveis e resistentes às pressões competitivas do mercado, em comparação aos atributos de produtos, pois se pautam nos valores e na essência da identidade corporativa (PÉREZ; DEL BOSQUE, 2014).

\subsection{ABORDAGENS DE MARCAS CORPORATIVAS}

A marca corporativa está relacionada ao conceito de identidade empresarial, que abrange as identidades corporativa, organizacional e visual, marca corporativa, comunicação corporativa ou total, imagem, personalidade corporativa e reputação (PÉREZ; DEL BOSQUE, 2014). No entanto, ainda que sejam conceitos correlatos, não podem ser considerados sinônimos, embora muitas vezes os termos sejam erroneamente considerados substitutos entre si (ABRATT; KLEYN, 2012; FETSCHERIN; USUNIER, 2012; URDE; GREYSER, 2016).

A mesma variabilidade do conceito macro de identidade organizacional também pode ser observada na definição e visão de marca corporativa sob diferentes perspectivas teóricas: estratégia de negócios e identidade organizacional (OLINS, 1989; BALMER, 2001; HATCH;

REAd | Porto Alegre - Vol. 23 - No Especial - Dezembro 2017 - p. 232-261 
SCHULTZ, 2003); design e identidade visual (ARGENTI, 2005; MOZOTA, 2003); comunicação corporativa e reputação (VAN RIEL; FOMBRUN, 2007); ativo intangível e análise do valor financeiro (KOTLER; PFOERTSCH, 2007), entre outras.

A pluralidade de conceitos contribui para certa ambiguidade do tema e falta de consenso sobre o significado exato de todos esses conceitos (BALMER, 2001; ABRATT; KLEYN, 2012; BALMER; ABRATT; KLEYN, 2016). A marca corporativa comunica e expressa a promessa da organização e representa a identidade projetada e desejada da organização (BALMER, 2001, 2012; BALMER; GRAY, 2003; VAN RIEL; FOMBRUN, 2007; HATCH; SCHULTZ, 2008; ABRATT; KLEYN, 2012; FETSCHERIN; USUNIER, 2012; URDE, 2013; URDE; GREYSER, 2016).

A reputação será a consequência desejada do processo de fortalecimento da marca corporativa, conferindo credibilidade, relevância e diferenciação (ABRATT; KLEYN, 2012; URDE; GREYSER, 2016). A identidade da marca e a reputação podem, então, ser consideradas os dois lados de uma mesma moeda, pois, enquanto a identidade trata de uma perspectiva interna, a reputação é essencialmente externa, e a distinção entre as duas depende principalmente da perspectiva adotada (URDE; GREYSER, 2016).

A estratégia de marca corporativa estabelece uma ponte entre as decisões estratégicas da empresa e a percepção e grau de confiança dos stakeholders, ou seja, entre a identidade e a reputação (ABRATT; KLEYN, 2012). A essência da identidade da organização e seus valores fundamentais compõem o centro da estratégia de marca corporativa e conecta o posicionamento estratégico, o diferencial competitivo, a comunicação e os relacionamentos da organização para a construção de uma reputação positiva (URDE; GREYSER, 2016).

Fetscherin e Usinier (2012), em amplo artigo de revisão bibliográfica sobre marcas corporativas, incluindo a análise de 264 publicações sobre o tema no período de 1969 a 2008, detectaram que cerca de $90 \%$ da literatura sobre marcas corporativas eram provenientes das áreas de negócios, gestão, arquitetura, artes e comunicação. Nota-se, então, a formação de um conceito multidisciplinar, porém que apresenta uma falta de consenso e de um quadro amplamente aceito na definição de marca corporativa (URDE, 2013).

Cada perspectiva referente ao conceito de marca corporativa tem a mesma base na identificação da corporação em diferentes níveis, da empresa por trás dos produtos a países e ideias, mas com pequenas nuances sobre as razões de ser e estratégias adotadas na sua construção. A marca corporativa pode ser uma ferramenta de navegação para os diversos stakeholders para uma coleção variada de propósitos, incluindo funcionários, investimentos e 
comportamento de compra do consumidor.

Balmer e Gray (2003), em artigo seminal sobre o tema, considerado como uma das referências mais abrangentes acerca da natureza, importância, tipologia e gestão de marca corporativa (FETSCHERIN; USUNIER, 2012), resumiram as diferentes correntes a partir da marca sendo vista como: sinais indicadores de propriedade (como brasões, na perspectiva do "remetente"); imagem e instrumentos de construção (processo de "persuasão" ligados também ao consumidor); símbolos associados a valores-chave (da organização e seus produtos e serviços; marcas vistas como garantia de qualidade ou segurança contra riscos); meios para construção de identidades individuais (a marca como atributo de identidade na perspectiva do consumidor); canal de consumo de experiências prazerosas.

$\mathrm{Na}$ busca por agregar estas diferentes nuances entre as frentes que abordam o tema, Balmer (2001) define a marca corporativa a partir do acrônimo em inglês $\mathrm{C}^{2}$ ITE - Cultural, Intrincate, Tangible, Ethereal, Commitment. Cultural, porque expressa valores; Complexa (Intricate), multidisciplinar e dimensional no relacionamento com múltiplos stakeholders; Tangível (Tangible), pois inclui produtos e serviços, bem como ações e comportamentos da organização; Etérea (Ethereal), ao prover associações emocionais e de estilo; e requer Comprometimento (Commitment) da liderança, áreas e profissionais para torná-la concreta.

Fetscherin e Usunier (2012) detectaram três abordagens principais nas definições de marca corporativa: transacional, interna e externa. A abordagem transacional é sobre corporate branding e o que a empresa faz (produto, serviços, patrocínio). A abordagem interna da empresa, focada na marca corporativa e o que a empresa é (identidade corporativa e/ou visual), bem como no perfil das pessoas que atrai (imagem como empregadora e aplicação). A abordagem externa explora a influência do mau comportamento corporativo (crime e crises) na reputação corporativa, na imagem corporativa, na performance (desempenho financeiro), na lealdade do cliente, e em como a organização é percebida pela opinião pública e sociedade. Tais abordagens principais se subsidiam em sete linhas nucleares de pesquisas sobre a marca corporativa com relação a: (1) produto, serviço e avaliação de patrocínio; (2) a identidade corporativa e visual; (3) imagem de emprego e aplicação; (4) crime corporativo; (5) o desempenho financeiro; (6) de extensão de marca; e (7) imagem corporativa.

Tendo em vista a categorização das frentes teóricas já estabelecidas (BALMER; GRAY, 2003), bem como a comparação proporcionada pela revisão da literatura, foram detectadas as cinco principais definições e abordagens relacionadas à marca corporativa, 
reforçando as diferenças sutis de cada frente, como mostra o Quadro 2.

Quadro 2 - Abordagens de definição da Marca Corporativa

\begin{tabular}{|lc|}
\hline \multicolumn{1}{|c|}{ Definições de Marca Corporativa } & $\begin{array}{c}\text { Abordagens } \\
\text { Baseado em BALMER; GRAY (2003) }\end{array}$ \\
\hline $\begin{array}{l}\text { A gestão da marca corporativa é o processo de construção de imagem } \\
\text { positiva sobre uma empresa e persuasão perante os consumidores e } \\
\text { demais públicos. }\end{array}$ & Imagem / Comunicação \\
\hline $\begin{array}{l}\text { A gestão da marca corporativa é a representação de símbolos associados } \\
\text { a valores-chave e cultura da empresa e de seus produtos e serviços. }\end{array}$ & $\begin{array}{c}\text { Valores-chave / Identidade / } \\
\text { Cultura }\end{array}$ \\
\hline $\begin{array}{l}\text { A gestão da marca corporativa está relacionada ao design do símbolo ou } \\
\text { representação visual da organização por trás de um produto ou serviço, } \\
\text { bem como a identidade visual de todas as comunicações e interações } \\
\text { promovidas pela empresa. }\end{array}$ & Sinais / Design \\
\hline $\begin{array}{l}\text { A gestão da marca corporativa é um meio de diferenciação entre os } \\
\text { concorrentes e construção de identidade individual e coletiva. }\end{array}$ & Diferenciação / Identidade \\
\hline $\begin{array}{l}\text { A gestão da marca corporativa é a construção da narrativa corporativa e } \\
\text { um condutor de experiências positivas com a organização. }\end{array}$ & Experiências / Comunicação \\
\hline
\end{tabular}

Fonte: elaborado pelos autores.

A definição conceitual adotada influencia fortemente as escolhas gerenciais relacionadas à marca corporativa como estratégia. Uma organização com uma abordagem interna e de alinhamento de valores de marca corporativa é mais fortemente orientada à identidade em um grau mais elevado (URDE; GREYSER, 2016), demonstrando uma abordagem interna do conceito de marca corporativa (FETSCHERIN; USUNIER, 2012). Em contraste, uma organização com uma abordagem mais fortemente orientada ao mercado é guiada pelas necessidades e desejos dos seus principais stakeholders (URDE; GREYSER, 2016). A percepção da marca, ou seja, de sua imagem e reputação em uma abordagem orientada ao mercado influencia o processo de estratégia da organização, numa abordagem externa do conceito de marca corporativa (FETSCHERIN; USUNIER, 2012). Conceitos voltados ao processo de construção da marca, como design, narrativas e diferenciação, podem ser considerados abordagens transacionais (FETSCHERIN; USUNIER, 2012), com ênfase no modelo de gestão.

\subsection{MOTIVOS PARA ADOTAR E INVESTIR EM MARCAS CORPORATIVAS}

A capacidade da marca corporativa de comunicar os valores, a cultura e comportamento da empresa, isto é, definir e expressar significado, é um dos motivos para adotá-la (AAKER, 2004; ARGENTI, 2005; BALMER; GRAY, 2003; EINWILLER; WILL, 2002; GUIMARÃES; PINHEIRO, 2008; HATCH; SCHULTZ, 2003, 2008; KNOX; 
BICKERTON, 2003; VAN RIEL; FOMBRUN, 2007; URDE, 2009; VANCE; ÂNGELO, 2007). Como face única de comunicação e relacionamento com os diversos stakeholders, a marca corporativa desempenha um papel unificador de identidade, discurso e imagens coerentes e consistentes.

$\mathrm{Na}$ relação com cada stakeholder, a marca corporativa pode apresentar benefícios específicos, tanto na geração de reputação positiva global, quanto na reputação com cada grupo específico (ABRATT; KLEYN, 2012). Na relação com os funcionários, favorece o senso de pertencimento, alinhamento e engajamento à missão, visão, plano estratégico, processos e comportamentos. Torna-se ainda catalisadora de mudanças da larga escala e de processos de reposicionamento, tais como fusões e aquisições e/ou novas estratégias de mercado (GOTSI; ANDRIOPOULOS; WILSON, 2008).

De acordo com o estudo qualitativo, envolvendo 23 executivos de 11 multinacionais na Europa, há uma importância crescente na gestão da marca corporativa, conforme fatores organizados em cinco principais grupos (EINWILLER; WILL, 2002):

(1) Crescente importância do mercado de capitais: uma forte marca corporativa e reputação favorável são consideradas pré-requisitos, e fundamentais influenciadores no valor das ações. Crescimento da importância dos fatores soft na avaliação da empresa por especialistas e mídia. Boa reputação como fator de decisão para a compra de ações.

(2) Guerra por Talentos: A reputação e identificação com a proposta de marca são altamente relevantes para atração e disputa pelos melhores profissionais. As pessoas procuram “empresas excelentes" centradas em uma cultura atraente e valores inspiradores.

(3) Necessidade de criar sinergia entre as marcas: Aumento da criticidade dos clientes levou ao aumento da importância dos valores corporativos, tais como integridade, solidez financeira, responsabilidade social e ambiental. A identificação da marca corporativa pode fortalecer as marcas de produto. Da mesma maneira, as marcas de produto como uma importante dimensão da marca corporativa e da reputação favorável da empresa.

(4) Coordenação e gestão de problemas de identidade em operações multinacionais: O posicionamento comum de valores e ideias atrelado à marca corporativa como guardachuva ajuda na integração dos discursos e na gestão de operações locais, aquisição de empresa, gestão de mudança. Necessidade de simplificação das mensagens-chave e discurso corporativo para o essencial, de forma a gerar coerência nas diversas operações.

(5) Demanda crescente por transparência: Aumento das obrigações legais de governança corporativa e divulgação de informações financeiras, somado ao aumento de pressão por

REAd | Porto Alegre - Vol. 23 - No Especial - Dezembro 2017 - p. 232-261 
transparência e interesse pelos mercados financeiros, mídia, internet e público em geral.

Processos de liberalização e o alto desenvolvimento de tecnologia da informação, bem como aumento de competitividade de mercado, reforçam a demanda por transparência.

Com base no estudo de Einwiller e Will (2002) e na revisão teórica realizada, foram elencadas as variáveis relativas aos motivos para adotar a marca corporativa, que serviram como base para a elaboração da etapa empírica do presente estudo. Os principais motivos abordados na literatura como justificativa para adotar a estratégia de marca corporativa compõem as variáveis desse projeto. Para facilitar a gestão dos indicadores, as variáveis serão agrupadas em categorias, como mostra a Figura 1.

Figura 1 - Categoria e Motivos para adotar a Marca Corporativa

Guerra por Talentos (Employer Branding) ${ }^{1}$

- Atração e disputa pelos melhores profissionais - fator de decisão

- Retenção de talentos

Sinergia entre as marcas (produto e organização) ${ }^{2}$

- Marca corporativa pode fortalecer marcas de produtos

- Sinergia entre diferentes unidades de negócios e marcas de produtos

- Foco de investimento em verbas de promoção e comunicação

Atração de consumidores (B2C) ${ }^{3}$

- Identificação da proveniência do produto

- Conquistar a preferência e a fidelidade de um consumidor

Relações Comerciais (B2B) ${ }^{4}$

- Posicionamento e atração de clientes em empresas B2B

- Maior alavancagem de negociação com revendedores e fornecedores

Operações Multinacionais e Holdings $s^{5}$

- Identidade e posicionamento comum nos diferentes países

- Integração e gestão de mudança em fusões e aquisições

Reposicionamento estratégico e Gestão de Mudança ${ }^{6}$

- Reposicionamento comercial e externo

- Engajamento interno para a mudança

(HARRIS; CHERNATONY, 2001; ENNWILLER; WILL, 2002; BALMER; GRAY, 2003; HATCH; SCHULTZ, 2003, 2008; AAKER, 2004; EDWARDS, 2010; CORTE; MANGIA, 2011 ;

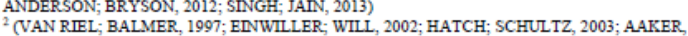
2004; KAY, 2006; VAN RIEL; FOMBRUN, 2007; MUZELLEC; LAMBKNN, 2009)

(KDNG, 1991; EDNWILLER; WILL, 2002; BALMER; GRAY, 2003; AAKER, 2004; KAY, 2006 ; GL YNN; MOTION; BRODIE, 2007; GHEMAWAT, 2008)

(KNNG, 1991; KEL LER; MACHADO, 2006; GL YNN; MOTION; BRODIE, 2007; LEEK; CHRISTODOULIDES, 2011; SHEIKH; LIM, 2011)

S(OLNS, 1989; ENNWILLER; WILI, 2002; BALMER; GRAY, 2003; XIE; BOGGS, 2006; VAN RIEL; FOMBRUN, 2007; GHAURI et al, 2011)

(EDNWILLER; WILL, 2002; CHENEY et al, 2004; ARGENTI, 2005; VAN RIEL; FOMBRUN, 2007; GOTSI; ANDRIOPOULOS; WIL SON, 2008)
Demanda por transparência ${ }^{7}$

- Obrigações governança corporativa e divulgação de inf. financeiras

- Pressão por transparência pelo mercado, mídia, internet e em geral.

- Mundo interconectado e veloz

Face única de relacionamento com stakeholders ${ }^{8}$

- Integração de discurso e posicionamento único

- Diferenciação da organização perante os stakeholders

Responsabilidade Social e Sustentabilidade ${ }^{9}$

- Demanda por valores de responsabilidade socioambiental.

- Pressão da sociedade e opinião pública pela atuação sustentável

- Relacionamento com a comunidade

Aumentar valor no Mercado de Capitais $^{10}$

- Pré-requisito de marca corporativa forte e reputação favorável

- Influência no valor das ações

- Boa imagem na avaliação da empresa por formadores de opinião

- Reputação como fator de desempate para compra de ações Identidade Organizacional ${ }^{11}$

- Capacidade da marca de comunicar valores e cultura

- Senso de pertencer e formação de identidade dos funcionários Imagem e Reputação ${ }^{12}$

- Mecanismo para construção de reputação favorável

- Prevenção de crises

- Valor de Marca como ativo intangivel (Brand Equity)

7 (HARRIS; CHERNATONY, 2001; HATCH; SCHULTZ, 2003, 2009; ARGENTI, 2005) "(EINWIILER; WILL, 2002; BALMER; GRAY, 2003; AAKER, 2004; VAN RIEL; FOMBRUN, 2007; HATCH; SCHUL TZ, 2008; PÉREZ; DEL BOSQUE, 2014; BALMER; ABRATT; KLEYN, 2016)

'(EINWILLER; WILL, 2002; BALMER; GRAY, 2003; AAKER, 2004; HATCH; SCHUL TZ, 2008, GUPTA; KUMAR, 2013)

"11 (EDNWILLER; WILL, 2002; KOTLER; PFOERTSCH, 2007) "(OLNS, 1989; BALMER; GRAY, 2003; KNOX; BICKERTON, 2003 ; URDE, 2003, 2009; VA

BOSQUE, 2014)
${ }_{12}$ (OLNS, 1989; ENWILLER; WILL, 2002; BALMER; GRAY, 2003; KNOX; BICKERTON, 2003; AAKER, 2004; KOTLER; PFOERTSCH, 2007; VAN RIEL; FOMBRUN, 2007; HATCH; SCHULTZ, 2008; BALMER; ABRATT; KLEYN, 2016)

Fonte: elaborado pelos autores.

Na leitura de Urde (2013), a ascensão de marcas corporativas tem sido impulsionada por seu poder como um elemento de estratégia, um recurso, uma ferramenta competitiva, um contribuinte para o desempenho da marca, uma fonte de valor/patrimônio e veículo de marketing integrado de nível. No entanto, sua construção varia de processos intuitivos, informais e pouco planejados, até processos orgânicos e intencionais, sendo utilizada como catalisadora do discurso organizacional e do posicionamento estratégico (BLOMBÄCK; 
RAMÍREZ-PASILLAS, 2012). O mapeamento extensivo dos motivos para a adoção da marca corporativa deu origem ao questionário utilizado neste estudo, aplicado para entender as sutilezas na percepção dos executivos investigados sobre o tema, bem como as abordagens predominantes no cenário nacional.

\section{METODOLOGIA}

Para se responder à pergunta-problema deste estudo de caráter descritivo (MATTAR, 1996; SAMARA; BARROS, 1997) - Quais são os principais motivos para se adotar o corporate branding - fez-se o uso de uma pesquisa quantitativa, por meio de uma aplicação de questionário (survey) no público pretendido: executivos brasileiros atuantes no Brasil. A escolha pela pesquisa quantitativa se justifica por ela possuir um viés estatístico que organiza, sumariza e interpreta dados numéricos coletados (MARTINS; THEÓPHILO, 2007).

O questionário foi construído especificamente para os fins desta pesquisa seguindo os passos propostos por Lakatos e Marconi (2003) ao relacionar o processo com o nível teórico. A catalogação extensiva dos motivos de adoção de marca corporativa, mapeados na revisão da literatura, deu origem a listagem de 26 principais motivos agrupados em 12 categorias, conforme análise e entendimento técnico dos autores. Esses motivos foram transformados em afirmativas para resposta em escala do tipo Likert, de 5 pontos, com o objetivo de avaliar o grau de concordância dos respondentes como cada uma delas e duas variáveis de controle, bem como uma aberta para comentários adicionais. Também foi utilizado como base as distintas conceituações de marca corporativa, a fim de mapear a escola preponderante entre os pesquisados, e os públicos impactados pela marca corporativa para avaliar se a estratégia tem como foco algum stakeholder específico.

Dessa forma, como mostra a Figura 2, a primeira parte do questionário era composta pelos itens analisados referentes ao tema central da pesquisa. A segunda parte do questionário é de qualificação da amostra, incluindo as variáveis que podem interferir na percepção sobre a marca, composta por 12 questões.

Antes da aplicação do questionário, procedeu-se um pré-teste com nove respondentes e dois especialistas no tema. A pesquisa foi disponibilizada pelo site Survey Monkey, no período de 14 de maio a 20 de junho de 2014, e teve caráter descritivo, com corte transversal, isto é, buscou-se a identificação e descrição dos objetivos de pesquisa, em uma coleta pontual

REAd | Porto Alegre - Vol. 23 - No Especial - Dezembro 2017 - p. 232-261 
e única na amostra. As questões afirmativas sobre os motivos e as alternativas da questão de múltipla escolha eram ordenadas de forma aleatória a cada acesso ao questionário.

Figura 2 - Elaboração da Survey a partir do referencial teórico

\begin{tabular}{|c|c|}
\hline $\begin{array}{c}\text { Os } 12 \text { motivos para marca } \\
\text { corporativa }\end{array}$ & $\begin{array}{c}\text { - } 26 \text { questões afirmativas em escala de Likert de } 5 \\
\text { pontos em escala de concordância. } \\
\text { - } 2 \text { questões afirmativas desfavoráveis para controle }\end{array}$ \\
\hline $\begin{array}{c}\text { Distintas conceituações de } \\
\text { marca corporativa }\end{array}$ & $\begin{array}{c}\text { Questão de múltipla escolha quanto à melhor } \\
\text { definição de marca corporativa }\end{array}$ \\
\hline Impacto da marca em distintos & $\begin{array}{c}\text { - Listagem de } 12 \text { stakeholders; mensuração de grau } \\
\text { de importância da marca é a cada um deles - escala } \\
\text { públicos }\end{array}$ \\
\hline
\end{tabular}

Fonte: elaborado pelos autores.

A amostra se configurou como não probabilística, isto é, sem propósitos inferenciais. Segundo Netto (2008) elas são compostas por acaso e escolhidas porque representam "o bom julgamento" da população. No caso deste estudo em questão, ela ainda foi por conveniência, intencional, por tipicidade e do tipo snow ball. A conveniência se observa no método de comunicação e divulgação: mailing à pós-graduação da FEA-USP, redes de contato dos pesquisadores, abordagem por redes de relacionamento e indicações, uso do site Linkedin, por meio de mensagem direta e individual para profissionais cadastrados na rede social que se enquadravam no perfil, bem como avisos em grupos de executivos, além da aplicação presencial em três turmas de pós-graduação (11 questionários).

A intencionalidade e catalogação da amostragem por tipicidade se justifica na seleção do subgrupo da população e no direcionamento intencional do questionário ao público-alvo pretendido: gestores dos seguintes níveis hierárquicos: Presidência, Sócio, Vice-Presidência, Diretoria e Gerência. Por fim, o tipo snow ball (FREITAS; OLIVEIRA, 2000) ocorre quando os participantes iniciais indicam novos participantes, ocasionando um efeito "bola de neve".

Ao final da fase de coleta chegou-se a um total de 379 respostas, sendo que 61 delas estavam incompletas, sem apresentar a identificação do cargo e 43 apresentaram cargo fora do perfil desejável (não gestores) impossibilitando a confirmação de serem enquadradas no perfil desejado. Realizado esse primeiro filtro, atingiram-se 275 respostas válidas, isto é, com todas as questões respondidas e dentro do perfil estabelecido.

\section{ANÁLISE E DISCUSSÃO DOS DADOS}

REAd | Porto Alegre - Vol. 23 - No Especial - Dezembro 2017 - p. 232-261 
A primeira etapa da análise dos dados concentrou-se na qualificação descritiva da amostra, em duas vertentes principais: o perfil dos respondentes e o perfil das empresas onde atuam. Demograficamente a amostra se apresentou adequada com o panorama executivo do mercado aberto e a tradicional estrutura com formato piramidal (INOJOSA, 2013): a maioria dos executivos entrevistados $(50,5 \%)$ ocupam o nível gerencial, uma quantidade intermediária de diretores (36,7\%) e um número reduzido de profissionais na Presidência e VicePresidência $(9,8 \%)$. Os sócios-diretores constituem a minoria $(2,9 \%)$ dos respondentes. Mais da metade dos respondentes são homens $(56,9 \%)$.

Quanto à área de atuação, os respondentes pertencem aos mais diferentes setores, com alta concentração no Administrativo, Comercial, Comunicação, Marketing e Recursos Humanos. A maioria absoluta dos entrevistados atua em alguma organização, sendo que apenas 0,4\% não está empregado atualmente, e 1,5\% em atuação autônoma neste período.

Aproximadamente $47 \%$ afirma trabalhar em empresas grandes, $30 \%$ em empresas médias e o restante em empresas pequenas conforme declaração do próprio entrevistado, uma vez que não foi apresentado critério de qualificação do tamanho da empresa. Mais de $60 \%$ dos respondentes trabalha em empresas nacionais, com atuação apenas no país ou com operações no exterior, enquanto apenas $38,4 \%$ afirma trabalhar em empresas de origem estrangeira.

A maioria absoluta dos entrevistas, 90\%, atua na região sudeste, provavelmente um efeito da amostra por conveniência. No entanto, a região sudeste já concentra praticamente metade de todas as empresas brasileiras, de acordo com o Empresômetro 2013, relatório anual divulgado pelo Instituto Brasileiro de Planejamento e Tributação (IBPT) com o perfil empresarial brasileiro (AMARAL; OLENIKE; AMARAL, 2013). Vale destacar que os dados do IBPT abrangem operações de todos os portes, incluindo empresas individuais, microempresas e entidades públicas e privadas. Pelo perfil do público-alvo da pesquisa, composto por executivos de pequenas, médias e grandes empresas, é provável que este percentual de concentração nos estados do sudeste seja ainda maior.

Para a composição do quadro geral dos motivos e stakeholders, inicialmente foi realizada a análise de confiabilidade da pesquisa, por meio do alfa de Cronbach que apresentou um nível de 0,909 , o que coloca a confiabilidade da pesquisa em um nível muito alto de consistência interna. Ao realizar a análise, de todas as variáveis, registrando qual seria o impacto no alfa de Cronbach caso a variável em questão fosse excluída do estudo, nota-se que os altos índices são mantidos, confirmando a confiabilidade da pesquisa. Vale destacar 
que a exclusão das variáveis de controle incluídas no estudo, questões afirmativas com a declaração contrária da importância da marca, não possui nenhum impacto no resultado final.

$\mathrm{Na}$ primeira pergunta do questionário, ainda não integrante à escala extensiva da catalogação de motivos principais, foram apresentadas 10 afirmativas, das quais o respondente poderia escolher as três que acreditasse possuir maior impacto positivo nos negócios de uma companhia, a fim de entender em termos de benefícios práticos de gestão percebidos. Como mostra o resultado na Tabela 1, criar diferenciação em relação ao concorrente é o principal impacto positivo percebido apontado pela maioria dos entrevistados (57,5\%), em linha com as justificativas ligadas ao marketing, em cenários de rápida similaridade de ofertas e produtos (AAKER, 2004; HATCH; SCHULTZ, 2003; KING, 1991), bem como a construção de um posicionamento único na expressão dos valores e essência da empresa (HATCH; SCHULTZ, 2003; KNOX; BICKERTON, 2003; URDE, 2003, 2009).

Tabela 1 - Impactos positivos da marca corporativa percebidos por executivos brasileiros

\begin{tabular}{lcc}
\hline \multicolumn{1}{c}{ Objetivos e desafios } & Frequência & \% \\
\hline Criar diferenciação em relação aos concorrentes & 158 & $57,5 \%$ \\
\hline Atrair e reter talentos & 133 & $48,4 \%$ \\
\hline Atrair consumidores & 121 & $44,0 \%$ \\
\hline Gerar recurso / valor intangível da organização & 76 & $27,6 \%$ \\
\hline $\begin{array}{l}\text { Melhorar diálogo e influência com formadores de opinião e } \\
\text { stakeholders-chave }\end{array}$ & 75 & $27,3 \%$ \\
\hline Apoiar inserção de novos produtos no mercado & 73 & $26,5 \%$ \\
\hline $\begin{array}{l}\text { Possibilitar melhores relações comerciais com } \\
\text { fornecedores e distribuidores }\end{array}$ & 69 & $25,1 \%$ \\
\hline Apoiar gestão de crises e recuperação após eventual crise & 39 & $14,2 \%$ \\
\hline Atuar mais fortemente em Sustentabilidade e Responsabilidade Social & 37 & $13,5 \%$ \\
\hline $\begin{array}{l}\text { Apoiar a resposta por transparência e velocidade dos meios de } \\
\text { comunicação }\end{array}$ & 22 & $8,0 \%$ \\
\hline Outro (especifique) & 4 & $1,5 \%$ \\
\hline Nenhum impacto relevante nos negócios & 0 & $0,0 \%$ \\
\hline \multicolumn{1}{c}{ Fonte: elaborado pelos autores. } & &
\end{tabular}

Em segundo lugar, escolhido por um número expressivo dos respondentes da amostra $(48,4 \%)$ aparece atrair e reter profissionais, o que reforça a presença do conceito de employer brand na agenda do porquê construir a marca corporativa (AMBLER; BARROW, 1996; BACKHAUS; TIKOO, 2004; SINGH; JAIN, 2013).

Em terceiro lugar, apontado por $44 \%$ da amostra, a atração de consumidores para a companhia figura como um dos principais impactos positivos, comprovando uma das principais origens da abordagem por marcas corporativas a partir do aumento da expectativa 
das pessoas sobre as empresas que estão por trás dos produtos e serviços consumidos e o processo de identificação com a proposta de valor das marcas (AAKER, 2004; BALMER; GRAY, 2003; KAY, 2006; KING, 1991).

Atrair talentos e consumidores, apontado como relevante pelos executivos brasileiros, corroboram com os achados de Einwiller e Will (2002) no que tange à guerra por talentos e a sinergia entre marcas, uma vez que menciona o aumento da criticidade das pessoas em relação às organizações. Em contrapartida, o aspecto referente à demanda crescente por informação e transparência, uma das tendências apontadas pelo estudo de Einwiller e Will (2002) foi o que recebeu menor atenção na escolha dos executivos brasileiros, por apenas 1,5\% dos entrevistados. Talvez o aspecto temporal seja uma justificativa para esta diferença, pois, no início dos anos 2000 estava-se no auge das mudanças provocadas pela internet e tecnologia.

A pressão pela postura voltada à responsabilidade socioambiental, um item presente na explicação sobre a importância da marca corporativa como demonstração do posicionamento da organização, também não é um dos itens mais relevantes na percepção dos entrevistados (AAKER, 2004; ARGENTI, 2005; VAN RIEL; FOMBRUN, 2007), sendo o segundo item menos citado, por 13,5\% da amostra. Assim como o caráter instrumental da marca corporativa e reputação em cenários de crise (VAN RIEL; FOMBRUN, 2007), apontado por apenas $14,2 \%$.

Tais resultados dão indícios de que a maior parte dos profissionais percebe a marca corporativa como mecanismo para estabelecer uma forte presença no mercado, e por esta diferenciação, atrair stakeholders primários como talentos e consumidores que estão diretamente relacionados aos resultados da empresa. A marca corporativa como ferramenta de comunicação e reforço de outros atributos é percebida em segundo plano.

Em seguida, foram apresentadas aos respondentes da pesquisa as variáveis relacionando como é visto o papel da marca corporativa na estratégia de negócios da empresa. Uma vez que duas variáveis foram inseridas para efeitos de controle, foram consideradas para a análise somente as 26 afirmativas que oferecem o panorama de como o tema é tratado no mercado brasileiro. Para garantir a isenção das respostas, o questionário online foi formulado para que a posição das variáveis fosse rearranjada aleatoriamente para cada participante diferente.

A fim de mapear os itens considerados mais relevantes, foi utilizada a tabulação ponderada para perguntas com escalas diferenciais, atribuindo peso para cada indicador da escala Likert, compreendendo o cálculo da média rating resultante do quociente entre a 
somatória de frequência versus peso pela base total da amostra (SAMARA; BARROS, 1997), como mostra a Figura 3.

Figura 3 - Escala de motivos para adotar a marca corporativa

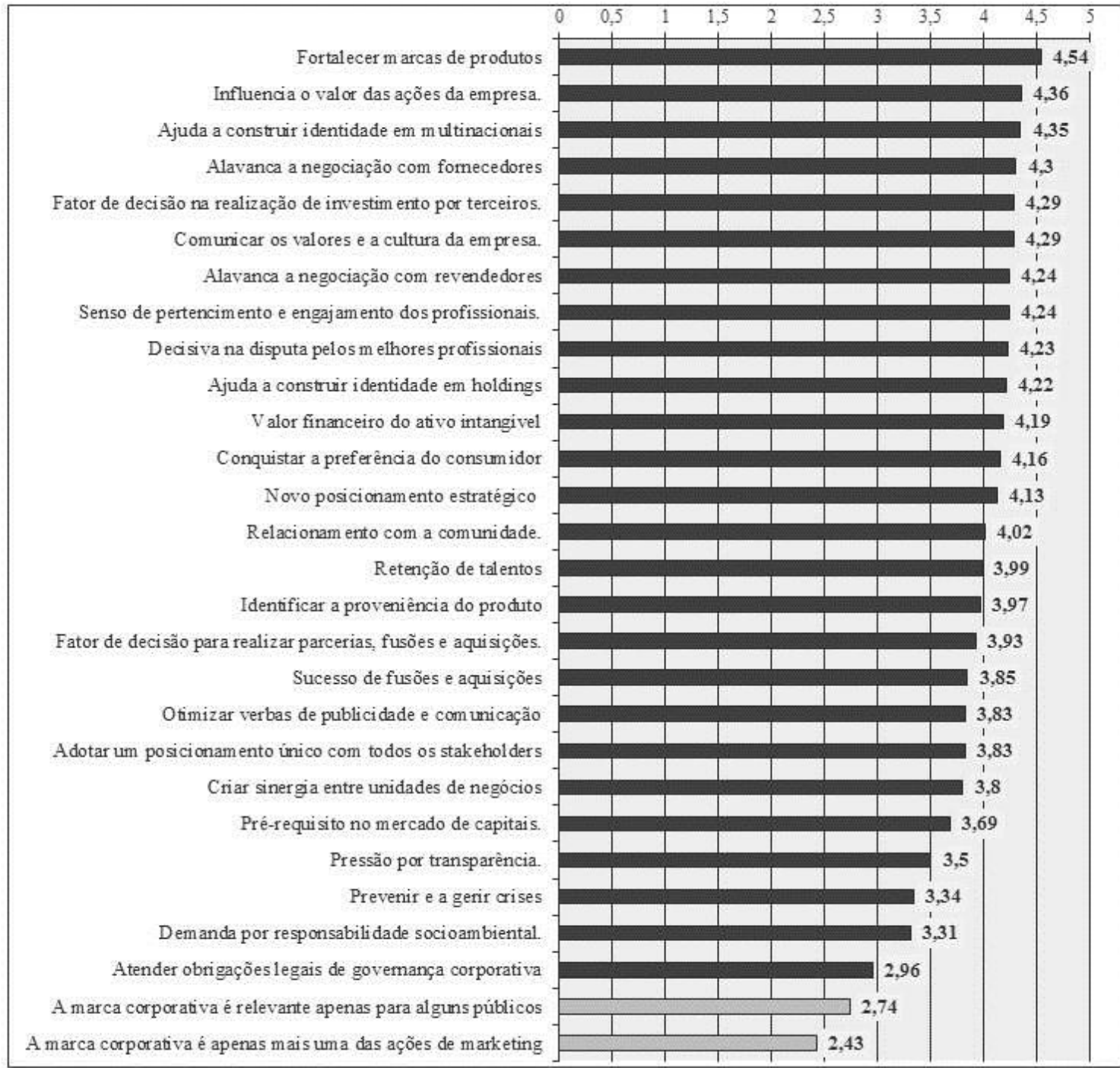

Fonte: Elaborado pelos autores

É possível notar que, apesar de existirem variáveis correspondentes entre a primeira e a segunda partes do questionário, não é possível distinguir uma correlação direta entre elas. $\mathrm{O}$ principal critério refere-se a marketing e fortalecimento da marca de produto, com o mais alto índice de avaliação $(4,54)$, novamente confirmando a origem da marca corporativa como resposta às novas exigências de competitividade (AAKER, 2004; HATCH; SCHULTZ, 2003; KING, 1991). A força da marca corporativa na valorização da empresa figura como um dos itens principais $(4,36)$, em linha com algumas das correntes sobre a marca e benefício direto no resultado da organização (KOTLER; PFOERTSCH, 2007). A construção da identidade em REAd | Porto Alegre - Vol. 23 - No Especial - Dezembro 2017 - p. 232-261 
organizações multinacionais também é bastante valorizada, como resposta das teorias voltadas para a estratégia de organizações (BALMER, 2001, 2008; OLINS, 1989; VAN RIEL; BALMER, 1997; VAN RIEL; FOMBRUN, 2007).

Contudo, quando se observam as variáveis menos valorizadas, encontram-se tópicos semelhantes às da primeira parte da pesquisa, com baixos índices para a marca corporativa relacionada à responsabilidade social e prevenção de crises, além do baixo reconhecimento como forma de atender as obrigações legais de governança corporativa, este último um dos subitens apresentados por (EINWILLER; WILL, 2002).

Ao listar uma ampla gama de motivos defendidos na literatura para a utilização da marca corporativa como estratégia, buscou-se obter uma visão extensiva desses motivos e observar as nuances sutis quanto sua valorização. A fim de complementar a análise, torna-se interessante observar como estes motivos podem ser agrupados e reduzidos a partir das respostas dos entrevistados, dando origem a dimensões latentes. Para tanto, utilizou-se a Análise Fatorial Exploratória (EFA), técnica multivariada de interdependência, cujo objetivo é identificar a estrutura inerente existente entre as variávei consideradas na análise (HAIR; ANDERSON; TATHAN, 2007)

Essa técnica estatística é indicada quando os pesquisadores pretendem descobrir quais variáveis na análise dão origem a subconjuntos coerentes, relativamente independentes uns dos outros. Esses subconjuntos, os chamados fatores, são compostos por variáveis altamente correlacionadas entre si, mas, ao mesmo tempo, razoavelmente independentes dos outros subconjuntos. Os fatores são considerados com o reflexo dos processos subjacentes que geram as correlações obsevadas entre as variáveis do conjunto (TABACHNICK; FIDELL, 2013).

Ao se reduzir a quantidade de variáveis em agrupamentos de fatores, maximiza-se o poder de explicação do conjunto de todas as variáveis, para então ser possível identificar subgrupos de questões que avaliam uma mesma habilidade ou capacidade cognitiva ou um comportamento (PASQUALI, 2005). Foram identificados seis fatores principais, como mostra a Tabela 2, agrupados considerando o resultado de carga fatorial acima de 0,5, exceto no Fator 1 por conta da relevância do item para a composição do fator.

A análise fatorial aplicada não teve o objetivo de validar um instrumento replicável, mas de entender a estrutura subjacente de importância dos 26 motivos mapeados para adoção de marca corporativa, bem como a redução deles em fatores. No caso da presente pesquisa é interessante notar que os fatores identificados podem ser alinhados pela tensão inerente das perspectivas interna ou externas da marca corporativa (BALMER; GREYSER, 2006; URDE;

REAd | Porto Alegre - Vol. 23 - No Especial - Dezembro 2017 - p. 232-261 
GREYSER, 2016), marcados principalmente por uma similaridade, ainda que tênue, de funcionalidade.

Tabela 2 - Análise Fatorial dos motivos pesquisados para a adoção da Marca Corporativa

\begin{tabular}{|c|c|c|c|c|}
\hline & \multicolumn{3}{|l|}{ Fator 1 - Marca Corporativa na interface de performance e reputação } & \multirow{2}{*}{$\begin{array}{l}\text { Categorias Originais } \\
\text { Aumentar valor no mercado } \\
\text { de capitais }\end{array}$} \\
\hline $\mathrm{C} 41$ & Uma marca corporativa forte é pré-requisito no mercado de capitais. & 0,732 & 10 & \\
\hline C19 & $\begin{array}{l}\text { A marca corporativa cria senso de pertencimento e engajamento dos } \\
\text { profissionais. }\end{array}$ & 0,64 & 11 & Identidade organizacional \\
\hline $\mathrm{C} 27$ & $\begin{array}{l}\text { A marca corporativa é uma alternativa eficiente para criar sinergia entre } \\
\text { unidades de negócios }\end{array}$ & 0,629 & 2 & $\begin{array}{l}\text { Sinergia entre as marcas } \\
\text { (produto e organização) }\end{array}$ \\
\hline $\mathrm{C} 18$ & A marca corporativa é a forma de identificar a proveniência do produto & 0,597 & 3 & Atração de consumidores \\
\hline $\mathrm{C} 28$ & $\begin{array}{l}\text { O investimento na marca corporativa possibilita otimizar verbas de } \\
\text { publicidade e comunicação }\end{array}$ & 0,55 & 2 & $\begin{array}{l}\text { Sinergia entre as marcas } \\
\text { (produto e organização) }\end{array}$ \\
\hline $\mathrm{C} 31$ & $\begin{array}{l}\text { A marca corporativa é relevante pelo valor financeiro do ativo } \\
\text { intangível }\end{array}$ & 0,52 & 12 & Imagem e reputação \\
\hline $\mathrm{C} 21$ & Uma marca corporativa forte ajuda a prevenir e a gerir crises & 0,42 & 12 & Imagem e reputação \\
\hline \multicolumn{5}{|c|}{ Fator 2 - Marca Corporativa na interface interna e alinhamento de valores } \\
\hline $\mathrm{C} 33$ & A marca corporativa ajuda a construir identidade em holdings & 0,74 & 5 & $\begin{array}{l}\text { Operações multinacionais e } \\
\text { holdings }\end{array}$ \\
\hline $\mathrm{C} 35$ & $\begin{array}{l}\text { A identificação com a marca corporativa é um dos principais } \\
\text { influenciadores na retenção de talentos }\end{array}$ & 0,723 & 1 & $\begin{array}{l}\text { Guerra por talentos } \\
\text { (employer brand) }\end{array}$ \\
\hline $\mathrm{C} 32$ & $\begin{array}{l}\text { A marca corporativa ajuda a atender a demanda por responsabilidade } \\
\text { socioambiental. }\end{array}$ & 0,596 & 9 & $\begin{array}{l}\text { Responsabilidade social e } \\
\text { sustentabilidade }\end{array}$ \\
\hline $\mathrm{C} 42$ & $\begin{array}{l}\text { A marca corporativa é uma ótima forma de comunicar os valores e a } \\
\text { cultura da empresa. }\end{array}$ & 0,585 & 11 & Identidade organizacional \\
\hline \multicolumn{5}{|c|}{ Fator 3 - Marca Corporativa na interface com múltiplos stakeholders } \\
\hline $\mathrm{C} 25$ & $\begin{array}{l}\text { A marca corporativa ajuda a organização a adotar um posicionamento } \\
\text { único com todos os stakeholders }\end{array}$ & 0,76 & 8 & $\begin{array}{l}\text { Face única e relacionamento } \\
\text { com stakeholders }\end{array}$ \\
\hline $\mathrm{C} 26$ & $\begin{array}{l}\text { A marca corporativa pode ser um fator de decisão na realização de } \\
\text { investimento por terceiros. }\end{array}$ & 0,739 & 10 & $\begin{array}{l}\text { Aumentar valor no mercado } \\
\text { de capitais }\end{array}$ \\
\hline $\mathrm{C} 39$ & $\begin{array}{l}\text { É importante investir na marca corporativa para conquistar a preferência } \\
\text { do consumidor }\end{array}$ & 0,537 & 3 & Atração de consumidores \\
\hline $\mathrm{C} 30$ & A marca corporativa forte alavanca a negociação com revendedores & 0,535 & 4 & Relações Comerciais \\
\hline \multicolumn{5}{|c|}{ Fator 4 - Marca Corporativa no reforço de posicionamento estratégico } \\
\hline $\mathrm{C} 23$ & $\begin{array}{l}\text { A marca corporativa forte é decisiva na disputa pelos melhores } \\
\text { profissionais }\end{array}$ & 0,625 & 1 & $\begin{array}{l}\text { Guerra por talentos } \\
\text { (employer brand) }\end{array}$ \\
\hline $\mathrm{C} 20$ & $\begin{array}{l}\text { Um novo posicionamento estratégico é fortalecido com a adoção de } \\
\text { marca corporativa. }\end{array}$ & 0,604 & 6 & $\begin{array}{l}\text { Reposicionamento } \\
\text { estratégico e gestão da } \\
\text { mudança }\end{array}$ \\
\hline $\mathrm{C} 43$ & Uma marca corporativa forte influencia o valor das ações da empresa. & 0,554 & 10 & $\begin{array}{l}\text { Aumentar valor no mercado } \\
\text { de capitais }\end{array}$ \\
\hline \multicolumn{5}{|c|}{ Fator 5 - Marca Corporativa na interface de governança } \\
\hline $\mathrm{C} 24$ & $\begin{array}{l}\text { A marca corporativa é fator de decisão para realizar parcerias, fusões e } \\
\text { aquisições. }\end{array}$ & 0,692 & 6 & $\begin{array}{l}\text { Reposicionamento } \\
\text { estratégico e gestão da } \\
\text { mudança }\end{array}$ \\
\hline $\mathrm{C} 29$ & $\begin{array}{l}\text { A marca corporativa é uma ferramenta para atender obrigações legais de } \\
\text { governança corporativa }\end{array}$ & 0,589 & 7 & Demanda por transparência \\
\hline \multicolumn{5}{|c|}{ Fator 6 - Marca Corporativa na interface transparente } \\
\hline $\mathrm{C} 45$ & A marca corporativa ajuda a responder à pressão por transparência. & 0,799 & 7 & Demanda por transparência \\
\hline $\mathrm{C} 44$ & $\begin{array}{l}\text { A marca corporativa é uma importante iniciativa para o sucesso de } \\
\text { fusões e aquisições }\end{array}$ & 0,757 & 6 & $\begin{array}{l}\text { Reposicionamento } \\
\text { estratégico e gestão da } \\
\text { mudança }\end{array}$ \\
\hline
\end{tabular}

Fonte: Elaborado pelos autores

Alguns fatores referem-se à gestão da identidade organizacional, como escolhas organizacionais estratégicas e sua expressão (ABRATT; KLEYN, 2012; URDE; GREYSER,

REAd | Porto Alegre - Vol. 23 - No Especial - Dezembro 2017 - p. 232-261 
2016). Como reforçam Urde e Greyse (2016), adotar uma perspetciva interna da marca implica no foco geral na identidade da marca, como explicitam os fatores 2 e 4 . Nesta perspectiva torna-se essencial o engajamento interno e o alinhamento das decisões gerenciais baseadas em elementos básicos da identidade. O papel e a função de uma plataforma de marca é proporcionar a organização e sua gestão com um modelo da identidade de marca corporativa, como expressão da intenção e posicionamento estratégico. Retrata o que a empresa é e a sua ambição.

Por exemplo, o Fator 2 engloba motivos mais relacionados ao alinhamento de valores da cultura organizacional, com maior ênfase de abordagem de dentro para fora da marca corporativa, incluindo questões de identidade em holdings, relacionamento com stakeholders internos - como funcionários e fornecedores - responsabilidade socioambiental, valores e a cultura da empresa. Já o Fator 4 evidencia a marca corporativa como elemento catalisador do posicionamento estratégico, que influencia as ações da empresa, a guerra por talentos e relacionamento com a comunidade. Esses fatores estão, ainda, em linha com a abordagem interna da marca (FETSCHERIN; USUNIER, 2012), ou seja, o que a empresa é e o perfil de stakeholders internos atraídos.

Já os fatores 1, 5 e 6 enfatizam a abordagem de fora para dentro da marca corporativa, com maior destaque para a reputação e a performance (ABRATT; KLEYN, 2012; URDE; GREYSER, 2016), tendo o ambiente externo e as demandas do mercado e dos stakeholders como principal ponto de partida. São fatores que também se mostram mais aderentes à abordagem externa da marca (FETSCHERIN; USUNIER, 2012), ou seja, na influencia em como é percebida pelos públicos, influencia em mau comportamento e crises de imagem e até mesmo no seu desempenho financeiro.

O Fator 1 carrega com maior representatividade o valor como ativo intangível ao destacar elementos de performance objetivos, tais como desempenho em mercado de capitais e gestão de verbas, e subjetivos, como engajamento dos profissionais, proveniência de produto e reputação para gestão de crises. Dessa forma, destaca o potencial da estratégia de marca corporativa em conferir elementos de reputação, tais como relevância, confiança, performance e engajamento para a organização (URDE; GREYSER, 2016). O Fator 5 também pode ser incluído nessa perspectiva, com destaque para questões de governança corporativa.

O caráter relacional e transacional da marca corporativa (FETSCHERIN; USUNIER, 2012), como conexão entre a empresa e os stakeholders, é subsidiado pelo fator 3 , que 
evidencia a marca corporativa como mecanismo de interface única com diferentes partes interessadas. Esse fator reforça a visão da marca corporativa como plataforma de conexão entre a identidade corporativa e a reputação (ABRATT; KLEYN, 2012; URDE; GREYSER, 2016).

Esse balanceamento entre a abordagem interna e externa da marca corporativa também é observada ao analisar as definições escolhidas pelos entrevistados. Sobre a abordagem de marca corporativa predominante entre os executivos brasileiros, como pode ser visto na Tabela 3, as definições mais fortes correspondem aos segmentos ligados à abordagem de valores-chave \& identidade, seguida pela abordagem de imagem \& reputação. Isto é, desponta como a abordagem mais citada o entendimento de que a marca corporativa auxilia a comunicar e posicionar o valor central da identidade da organização (URDE, 2003, 2009).

Tabela 3 - Abordagem de Marca Corporativa adotada por executivos brasileiros

\begin{tabular}{lcc}
\hline \multicolumn{1}{c}{ Definições } & Abordagem & Percentual \\
\hline $\begin{array}{l}\text { A gestão da marca corporativa é o processo de construção de imagem } \\
\text { positiva sobre uma empresa e persuasão perante os consumidores e } \\
\text { demais públicos. }\end{array}$ & $\begin{array}{c}\text { Imagem / } \\
\text { Reputação }\end{array}$ & $30,7 \%$ \\
\hline $\begin{array}{l}\text { A gestão da marca corporativa é a representação de símbolos } \\
\text { associados a valores-chave e cultura da empresa e de seus produtos e } \\
\text { serviços. }\end{array}$ & $\begin{array}{l}\text { Valores-chave / } \\
\text { Identidade }\end{array}$ & $36,9 \%$ \\
\hline $\begin{array}{l}\text { A gestão da marca corporativa está relacionada ao design do símbolo } \\
\text { ou representação visual da organização por trás de um produto ou } \\
\text { serviço, bem como a identidade visual de todas as comunicações e } \\
\text { interações promovidas pela empresa. }\end{array}$ & Sinais / Design & $6,9 \%$ \\
\hline $\begin{array}{l}\text { A gestão da marca corporativa é um meio de diferenciação entre os } \\
\text { concorrentes e construção de identidade individual e coletiva. }\end{array}$ & $\begin{array}{l}\text { Diferenciação / } \\
\text { Identidade }\end{array}$ & $11,3 \%$ \\
\hline $\begin{array}{l}\text { A gestão da marca corporativa é a construção da narrativa corporativa e } \\
\text { um condutor de experiências positivas com a organização. }\end{array}$ & $\begin{array}{l}\text { Experiências / } \\
\text { Comunicação }\end{array}$ & $14,2 \%$ \\
\hline
\end{tabular}

Fonte: Elaborado pelos autores

Em segundo lugar, a percepção positiva e a credibilidade gerada pela marca corporativa na mente dos stakeholders (KELLER, 2006), cujo real valor se traduz como ativo intangível (HARRIS; CHERNATONY, 2001; KOTLER; PFOERTSCH, 2007). A escola mais tradicional, focada no design, foi citada apenas por $7 \%$ dos entrevistados, o que denota avanço da visão de marcas corporativas calcadas no seu significado, muito além da identidade visual. Vale destacar que as definições foram construídas de forma a evidenciar as nuances de abordagens sobre marcas corporativas, a fim de mapear as preponderâncias de quais fatores seriam privilegiados na escolha dos executivos brasileiros. Nesse sentido, a pergunta foi formulada com o propósito de detectar tais nuances preferenciais das abordagens de marca corporativa, considerando vertentes contidas em definições como o acrônimo em inglês $\mathrm{C}^{2}$ ITE proposta por Balmer (2001), ou a tríade Cultura Organizacional, Imagem e Visão REAd | Porto Alegre - Vol. 23 - No Especial - Dezembro 2017 - p. 232-261 
Estratégica (HATCH; SCHULTZ, 2003, 2008). A necessidade de refinar as definições de marketing corporativo e de marca corporativa desponta uma das principais tendências da área, bem como a bifurcação dos conceitos e ênfases (BALMER; ABRATT; KLEYN, 2016).

\section{CONSIDERAÇÕES FINAIS}

As marcas corporativas, atualmente, representam mais do que apenas o símbolo para identificar uma empresa. Na velocidade e pressão por uma postura mais autêntica e uma interface mais intensa da organização no relacionamento com seus públicos, a marca corporativa torna-se o canal para compartilhar os princípios fundamentais de uma organização. A partir desta leitura acerca dos dados coletados pela survey, pode-se retomar os objetivos principais da pesquisa e afirmar que em relação à abordagem mais adotada de entendimento de marca corporativa pelos executivos brasileiros encontra-se justamente a marca relacionada a valores-chave e a cultura da organização, seguida da marca relacionada a imagem; ou seja, a marca é uma forma de expressão da cultura e dos valores organizacionais, bem como de persuasão e construção de uma imagem positiva no mercado por meio do relacionamento com os diferentes stakeholders.

No que concerne à identificação dos motivos percebidos como mais relevantes para a adoção da marca corporativa, a prioridade continua atrelada à visão mais tradicional do marketing, voltada para o potencial da marca corporativa em fortalecer as marcas de produto. No entanto, a visão da contribuição da credibilidade construída pela marca como impacto no resultado e no valor da empresa denota a visão ainda mais estratégica e abrangente deste ativo intangível. A capacidade de criar significado e alinhamento interno na construção de identidade em multinacionais, isto é, o posicionamento único de uma organização independente do local de atuação, complementa os motivos considerados mais relevantes. Esse conjunto de motivos colocados em destaque mostra uma visão multidisciplinar presente entre os executivos, com foco interno, em vendas e em resultados.

Pelos primeiros dois motivos percebidos como mais relevantes, fica evidenciado que a questão financeira é forte influenciador nas estratégias de corporate branding. Qualquer movimento nesse sentido aguarda um retorno econômico-financeiro à organização. Interessante, também, observar que a diferenciação se destaca como um dos principais impactos positivos que a marca corporativa agrega aos negócios, seguida por atração dos consumidores e atração de talentos.

REAd | Porto Alegre - Vol. 23 - No Especial - Dezembro 2017 - p. 232-261 
O presente estudo, por meio da identificação do agrupamento das varíáveis de motivos para adoção de marca corporativa, reforça a necessidade de integração entre a abordagem interna e externa de marca organizacional (URDE; GREYSER, 2016) como estratégia e elemento de conexão entre a expressão da identidade e da cultura organizacional e a imagem/reputação construída pelos stakeholders a partir das interações com a empresa (ABRATT; KLEYN, 2012). A marca corporativa somente ganha vida e relevância quando comunicada e o seu valor é percebido, assimilado e reconhecido pelos stakeholders, porém resultado da atitude concreta e essência da organização (ABRATT; KLEYN, 2012; URDE; GREYSER, 2016).

A pesquisa realizada aponta distintas tendências e abre espaço para estudos futuros. $\mathrm{O}$ esforço da modelagem de um questionário que abordasse o tema de maneira sintética, sem desconsiderar as múltiplas escolas teóricas envolvidas, por si só, já representaria uma contribuição no conhecimento do tema, pois evidenciou a evolução do conceito de marca corporativa, os campos de estudos em intersecção e classificou os motivos mapeados da bibliografia do tema em uma listagem única. O estudo também contribui para ampliar o conhecimento sobre como o conceito vem sendo entendido e aplicado no mercado brasileiro.

Como possibilidades de estudos futuros, sugerem-se análises comparativas com outras realidades para verificar se o entendimento e a importância da marca corporativa guardam fatores contingenciais advindos da cultura ou do institucionalismo vigente a cada contexto, bem como análises comparativas de fatores que influenciam a abordagem e estratégias de marca corporativa, como segmento, tipo de operação e tipologia de marca adotada da empresa e/ou formação, nível e área de atuação do entrevistado. Há ainda a possibilidade da mesma pesquisa ser aplicada em setores com forte regulamentação, que atuem com restrições de marketing ou com peculiaridades normativas.

\section{REFERÊNCIAS}

AAKER, D. A. Leveraging the corporate brand. California Management Review, v. 46, n. 3, p. 6-18, abr. 2004.

ABRATT, R.; KLEYN, N. Corporate identity, corporate branding and corporate reputations: Reconciliation and integration. European Journal of Marketing, v. 46, n. 7/8, p. 10481063, 2012.

AMARAL, G. L. do; OLENIKE, J. E.; AMARAL, L. M. F. do. Empresômetro: perfil

REAd | Porto Alegre - Vol. 23 - No Especial - Dezembro 2017 - p. 232-261 
empresarial brasileiro 2013. [s.l: s.n.].

AMBLER, T.; BARROW, S. The Employer brand. Journal of Brand Management, v. 4, p. 185-206, 1996.

ANDERSON, G.; BRYSON, J. The good employer: the image and the reality. International Labour and Employment Relations Association, n. 43, p. 19, 2012.

ARGENTI, P. A. Comunicação empresarial: a construção da identidade, imagem e reputação. 1a. ed. Rio de Janeiro: Elsevier Ltd, 2005.

ARGENTI, P. A; DRUCKENMILLER, B. Reputation and the corporate brand. Corporate Reputation Review, v. 6, n. 4, p. 368-374, 2004.

BACKHAUS, K.; TIKOO, S. Conceptualizing and researching employer branding. Career Development International, v. 9, n. 5, p. 501-517, 2004.

BALMER, J. M. T. Corporate identity, corporate branding and corporate marketing - seeing through the fog. European Journal of Marketing, v. 35, n. 3/4, p. 248-291, 2001.

BALMER, J. M. T. Identity based views of the corporation: Insights from corporate identity, organisational identity, social identity, visual identity, corporate brand identity and corporate image. European Journal of Marketing, v. 42, n. 9/10, p. 879-906, 2008.

BALMER, J. M. T. Explicating corporate brands and their management: reflections and directions from 1995. Journal of Brand Management, v. 18, n. 3, p. 180-196, dez. 2010. BALMER, J. M. T. Strategic corporate brand alignment: perspectives from identity based views of corporate brands. European Journal of Marketing, v. 46, n. 7/8, p. 1064-1092, 2012.

BALMER, J. M. T.; ABRATT, R.; KLEYN, N. Corporate brands and corporate marketing: emerging trends in the big five eco-system. Journal of Brand Management, v. 23, n. 1, p. 3-7, 2016.

BALMER, J. M. T.; GRAY, E. R. Corporate brands: what are they? What of them? European Journal of Marketing, v. 37, n. 7/8, p. 972-997, 2003.

BALMER, J. M. T.; GREYSER, S. Corporate marketing: integrating corporate identity, corporate branding, corporate communications, corporate image and corporate reputation. European Journal of Marketing, v. 40, n. 7/8, p. 730-741, 2006.

BAUMGARTH, C.; SCHMIDT, M. How strong is the business-to-business brand in the workforce? An empirically-tested model of "internal brand equity" in a business-to-business setting. Industrial Marketing Management, v. 39, n. 8, p. 1250-1260, nov. 2010.

BAZERMAN, M. H.; MOORE, D. Processo decisório. 7. ed. Rio de Janeiro - RJ: Elsevier

REAd | Porto Alegre - Vol. 23 - No Especial - Dezembro 2017 - p. 232-261 
Ltd, 2010.

BLOMBÄCK, A.; RAMÍREZ-PASILLAS, M. Exploring the logics of corporate brand identity formation. Corporate Communications: An International Journal, v. 17, n. 1, p. 7-28, 2012.

CHENEY, G.; CHRISTENSEN, L. T.; ZORN, T. E.; GANESH, S. Organizational communication in an age of globalization. Illinois: Waveland Press, 2004.

CORTE, V. Della; MANGIA, G. Strategic employer branding: brand and image Management as a Tool of Attractiveness for Talented Capital. China-USA Business Review, v. 10, n. 12, p. 1231-1252, 2011.

DAVIES, G.; CHUN, R. Gaps between the internal and external perceptions of the corporate brand. Corporate Reputation Review, v. 5, n. 2/3, p. 144-158, 1 out. 2002.

DOUGLAS, S. International brand architecture: development, drivers and design. Journal of International Brand Architecture, p. 1-14, 1999.

EDWARDS, M. R. An integrative review of employer branding and OB theory. Personnel Review, v. 39, n. 1, p. 5-23, 2010.

EINWILLER, S.; WILL, M. Towards an integrated approach to corporate branding: an empirical study. Corporate Communications: An International Journal, v. 7, n. 2, p. 100$109,2002$.

FETSCHERIN, M.; USUNIER, J. Corporate branding: an interdisciplinary literature review. European Journal of Marketing, v. 46, n. 5, p. 733-753, 25 maio 2012.

FREEMAN, R. E.; HARRISON, J.; WICKS, A. Managing for stakeholders: survival, reputation, and success. 1. ed. New Haven \& London: Yale University Press, 2007. FREITAS, H.; OLIVEIRA, M. O método de pesquisa survey. Revista de Administração, v. 35 , n. 3, p. 105-112, 2000.

GHAURI, P. N.; ELG, U.; TARNOVSKAYA, V.; FATIMA, W. Developing a market driving strategy for foreign markets: Internal capabilities and external activities.

Schmalenbach Business Review, v. 11, n. 3, p. 1-23, 2011.

GLYNN, M. S.; MOTION, J.; BRODIE, R. J. Sources of brand benefits in manufacturerreseller B2B relationships. Journal of Business \& Industrial Marketing, v. 22, n. 6, p. 400409, 2007.

GOTSI, M.; ANDRIOPOULOS, C.; WILSON, A. M. Corporate re-branding: is cultural alignment the weakest link? Management Decision, v. 46, n. 1, p. 46-57, 2008.

GUIMARÃES, R.; PINHEIRO, R. Branding: identidade, relações e valor de mercado. In:

REAd | Porto Alegre - Vol. 23 - No Especial - Dezembro 2017 - p. 232-261 
Gestão Integrada de Ativos Instangíveis. Rio de Janeiro - RJ: Qualitymark, 2008. p. 97121.

GUPTA, S.; KUMAR, V. Sustainability as corporate culture of a brand for superior performance. Journal of World Business, v. 48, n. 3, p. 311-320, 2013.

HAIR, J. F. J.; ANDERSON, R. E.; TATHAN, R. L. Análise multivariada de dados. Porto Alegre: Bookman, 2007.

HARRIS, F.; CHERNATONY, L. De. Corporate branding and corporate brand performance. European Journal of Marketing, v. 35, n. 3/4, p. 441-456, 2001.

HATCH, M. J.; SCHULTZ, M. Bringing the corporation into corporate branding. European Journal of Marketing, v. 37, n. 7/8, p. 1041-1064, 2003.

HATCH, M. J.; SCHULTZ, M. Taken brand initiative: how companies can align strategy, culture, and identity through corporate branding. 1. ed. San Francisco: Jossey-Bass, 2008.

HATCH, M. J.; SCHULTZ, M. Of bricks and brands. Organizational Dynamics, v. 38, n. 2, p. 117-130, abr. 2009.

INOJOSA, R. Intersetorialidade ea configuração de um novo paradigma organizacional.

Revista de Administração Pública, v. 2, n. 2, p. 35-48, 2013.

KAY, M. J. Strong brands and corporate brands. European Journal of Marketing, v. 40, n. 7/8, p. 742-760, 2006.

KELLER, K. L.; MACHADO, M. Gestão estratégica de marcas. São Paulo -SP: Pearson Prentice Hall, 2006.

KING, S. Brand building in the 1990s. Journal of Consumer Marketing, v. 8, n. 4, p. $43-$ $52,1991$.

KNOX, S.; BICKERTON, D. The six conventions of corporate branding. European Journal of Marketing, v. 37, n. 7/8, p. 998-1016, 2003.

KOTLER, P.; PFOERTSCH, W. Being known or being one of many: the need for brand management for business-to-business (B2B) companies. Journal of Business \& Industrial Marketing, v. 22, n. 6, p. 357-362, 2007.

LAKATOS, E. M.; MARCONI, M. de A. Metodologia científica. 5. ed. São Paulo -SP: Atlas, 2003.

LEEK, S.; CHRISTODOULIDES, G. A literature review and future agenda for B2B branding: Challenges of branding in a B2B context. Industrial Marketing Management, v. 40, n. 6, p. 830-837, ago. 2011.

MARTINS, G. de A.; THEÓPHILO, C. R. Metodologia da investigação científica para

REAd | Porto Alegre - Vol. 23 - No Especial - Dezembro 2017 - p. 232-261 
ciências sociais aplicadas. São Paulo -SP: Atlas, 2007.

MATTAR, F. N. Pesquisa de marketing: edição compacta. São Paulo -SP: Atlas, 1996.

MOZOTA, B. B. de. Design management: using design to build brand value and corporate innovation. New York - NY: Allworth Press, 2003.

MUZELLEC, L.; LAMBKIN, M. C. Corporate branding and brand architecture: a conceptual framework. Marketing Theory, v. 9, n. 1, p. 39-54, 1 mar. 2009.

NETTO, A. A. de O. Metodologia da pesquisa científica: guia prático para a apresentação de trabalhos acadêmicos. Florianópolis: Visual Books, 2008.

OLINS, W. Corporate identity making business strategy visible throught design. Boston: Harvard Business School Press, 1989.

PASQUALI, L. Análise fatorial para pesquisadores. Brasília: LabPAM, 2005.

PÉREZ, A.; DEL BOSQUE, I. R. Organizational and corporate identity revisited: toward a comprehensive understanding of identity in business. Corporate Reputation Review, v. 17, n. 1, p. 3-27, 2014.

SAMARA, B. S.; BARROS, J. C. de. Pesquisa de marketing: conceitos e metodologia. 2. ed. ed. São Paulo -SP: Makron Books, 1997.

SCHULTZ, M.; DE CHERNATONY, L. Introduction: the challenges of corporate branding. Corporate Reputation Review, v. 5, n. 2/3, p. 105-112, 1 out. 2002.

SHEIKH, A.; LIM, M. Engineering consultants' perceptions of corporate branding: A case study of an international engineering consultancy. Industrial Marketing Management, v. 40, n. 7, p. 1123-1132, out. 2011.

SINGH, A.; JAIN, S. Employer branding: a tool for motivating and retaining employees.

Indian Journal of Current Trends in Management Sciences, v. VI, p. 1-14, 2013.

TABACHNICK, B.; FIDELL, L. Using multivariate statistics. 6th edition. New York - NY: Harper Collins, 2013.

URDE, M. Core value-based corporate brand building. European Journal of Marketing, v. 37, n. 7/8, p. 1017-1040, 2003.

URDE, M. Uncovering the corporate brand's core values. Management Decision, v. 47, n. 4, p. 616-638, 2009.

URDE, M. The corporate brand identity matrix. Journal of Brand Management, v. 20, n. 9, p. 742-761, 2013.

URDE, M.; GREYSER, S. A. The corporate brand identity and reputation matrix: the case of the Nobel Prize. Journal of Brand Management, v. 23, n. 1, p. 89-117, 2016.

REAd | Porto Alegre - Vol. 23 - No Especial - Dezembro 2017 - p. 232-261 
VAN RIEL, C. B. M.; BALMER, J. M. T. Corporate identity: the concept, its measurement and management. European Journal of Marketing, v. 31, n. 5/6, p. 340-355, 6 jun. 1997. VAN RIEL, C. B. M.; FOMBRUN, C. J. Essentials of corporate communication:

implementing practices for effective reputation management. New York - NY: Routledge, 2007.

VANCE, P. D. S.; ÂNGELO, C. de. Reputação corporativa: uma revisão teórica. Revista de Gestão USP, v. 14, n. 4. p. 93-108, 2007.

XIE, H. Y.; BOGGS, D. J. Corporate branding versus product branding in emerging markets. Marketing Intelligence \& Planning, v. 24, n. 4, p. 347-364, jun. 2006. 